\title{
Quarterly Management Document FY19, 3rd Quarter, Physics-based Creep Simulations of Thick Section Welds in High Temperature and Pressure Applications
}

Thomas M Lillo, Wen Jiang

August 2019

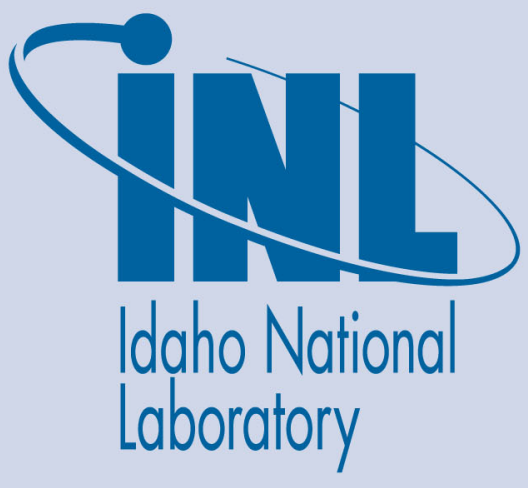

The INL is a U.S. Department of Energy National Laboratory operated by Battelle Energy Alliance 


\title{
Quarterly Management Document FY19, 3rd Quarter, Physics-based Creep Simulations of Thick Section Welds in High Temperature and Pressure Applications
}

\author{
Thomas M Lillo, Wen Jiang
}

August 2019

Idaho National Laboratory Idaho Falls, Idaho 83415

http://www.inl.gov

Prepared for the U.S. Department of Energy Office of Fossil Energy Under DOE Idaho Operations Office Contract DE-AC07-05ID14517 
Quarterly Management Document - FY19, $3^{\text {rd }}$ Quarter, Physics-based Creep Simulations of Thick Section Welds in High Temperature and Pressure Applications

Document \# INL/EXT-19-55168

\begin{tabular}{|c|c|c|c|c|}
\hline $\begin{array}{l}\text { WBS Element } \\
\text { C.B.10.02.02.40 }\end{array}$ & $\begin{array}{l}\text { Project Title } \\
\text { Physics-based Creep Simulations of } \\
\text { Thick Section Welds in High } \\
\text { Temperature and Pressure Applications }\end{array}$ & $\begin{array}{l}\text { Contract Numbe } \\
\text { FEAA90 }\end{array}$ & $\begin{array}{l}\text { Contract Start } \\
10 / 01 / 17\end{array}$ & $\begin{array}{l}\text { Contract End } \\
09 / 30 / 2019\end{array}$ \\
\hline \multicolumn{2}{|c|}{$\begin{array}{l}\text { Performer Name and Address } \\
\text { Thomas Lillo } \\
\text { Idaho National Laboratory } \\
\text { P.O. Box } 1625 \\
\text { Idaho Falls, ID } 83415\end{array}$} & $\begin{array}{l}\mathrm{Pr} \\
\mathrm{Tl}\end{array}$ & $\begin{array}{l}\text { oal Investigator( } \\
\text { nas Lillo }\end{array}$ & \\
\hline
\end{tabular}

\section{BUDGET AND COST REPORT}

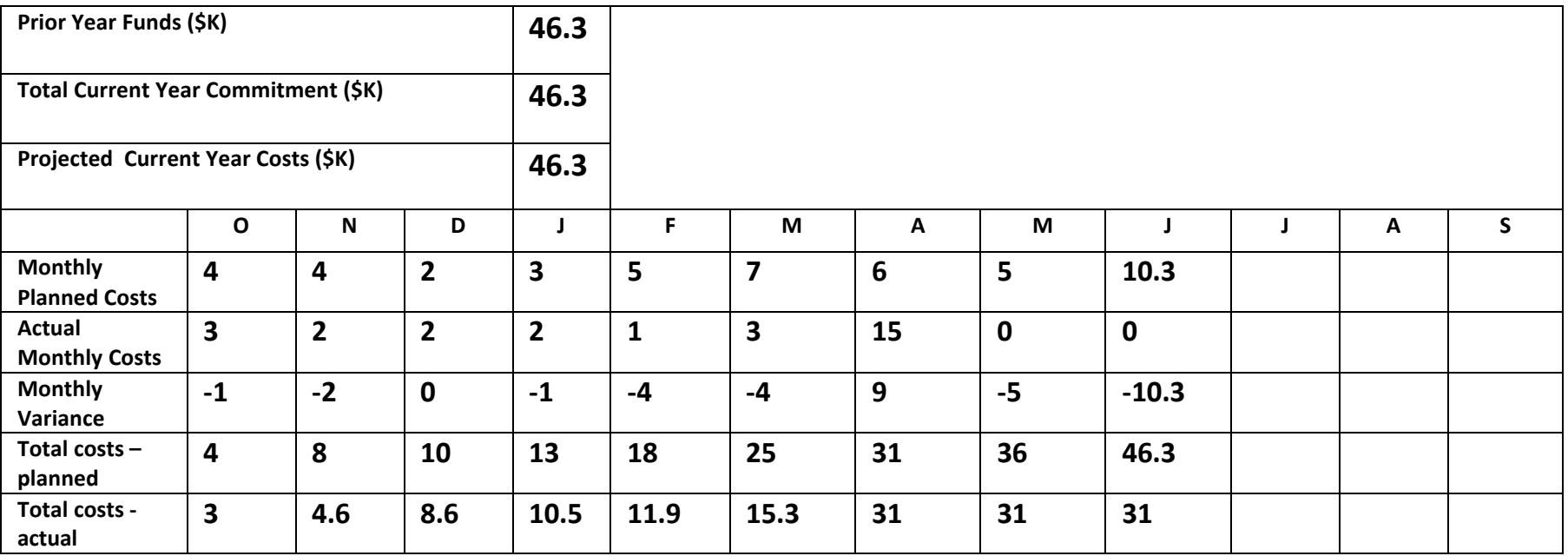

\section{MILESTONE REPORT}

\begin{tabular}{|c|l|l|c|c|}
\hline $\begin{array}{c}\text { Milestone } \\
\text { Designation }\end{array}$ & Milestone Description & Due Date & $\begin{array}{c}\text { Revised Due } \\
\text { Date }\end{array}$ & $\begin{array}{c}\text { Completion } \\
\text { Date }\end{array}$ \\
\hline A & Evaluate current MOOSE capabilities & $09 / 30 / 2015$ & & $09 / 30 / 2015$ \\
\hline B & Complete Alloy 617 weld characterization & $10 / 30 / 2015$ & & $11 / 18 / 2015$ \\
\hline C & Receipt of Alloy 740H plates & $10 / 30 / 2015$ & & $11 / 05 / 2015$ \\
\hline D & Complete welds in Alloy 740H & $11 / 16 / 2015$ & $7 / 31 / 2016$ & $7 / 31 / 2016$ \\
\hline
\end{tabular}




\begin{tabular}{|c|c|c|c|c|}
\hline $\mathrm{E}$ & Characterize Alloy $740 \mathrm{H}$ welds & $02 / 01 / 2016$ & $09 / 30 / 2016$ & $9 / 02 / 2016$ \\
\hline $\mathrm{F}$ & Creep model development - Stage 1 & $09 / 30 / 2016$ & & $9 / 30 / 2016$ \\
\hline $\mathrm{G}$ & Creep Model Development - Stage 2 & $8 / 29 / 2017$ & $2 / 28 / 2019$ & $1 / 15 / 2019$ \\
\hline $\mathrm{H}$ & Calibration of Secondary creep - Alloy 617 & 9/30/2017 & $3 / 31 / 2019$ & Eliminated \\
\hline I & Stress Drop Tests & $2 / 01 / 2017$ & $5 / 31 / 2018$ & $6 / 28 / 2018$ \\
\hline J & $\begin{array}{l}\text { Characterization of creep failure } \\
\text { mechanisms }\end{array}$ & $4 / 01 / 2017$ & $04 / 30 / 2018$ & $5 / 04 / 2018$ \\
\hline $\mathrm{K}$ & $\begin{array}{l}\text { Secondary creep calibration for welds - } \\
\text { Alloy } 617\end{array}$ & $5 / 30 / 2018$ & $4 / 15 / 2019$ & Eliminated \\
\hline $\mathrm{L}$ & $\begin{array}{l}\text { Creep model development - Completion of } \\
\text { Stage } 3\end{array}$ & $8 / 30 / 2018$ & $8 / 16 / 2019$ & \\
\hline $\bar{M}$ & $\begin{array}{l}\text { Creep simulation of a welded joint in Alloy } \\
740 \mathrm{H}\end{array}$ & $9 / 30 / 2018$ & $8 / 30 / 2019$ & \\
\hline $\mathrm{N}$ & $\begin{array}{l}\text { Validation of creep simulation model via an } \\
\text { Alloy } 740 \mathrm{H} \text { weld consisting of refined } \\
\text { microstructure }\end{array}$ & $9 / 15 / 2018$ & $9 / 15 / 2019$ & \\
\hline
\end{tabular}

\section{TECHNICAL HIGHLIGHTS}

\section{Milestone L, "Creep model development - Completion of Stage 3"}

The main focus on this task during this quarter has been on how to incorporate tertiary creep into the model. The exact mechanism resulting in the transition to tertiary creep has not been definitively identified, making a physics-based model difficult to incorporate into the simulation. Shen, 2015 has used the approach that the total creep strain can be considered to be the summation of creep due to dislocation processes and diffusional processes:

$$
\varepsilon^{\text {creep }}=\varepsilon^{\text {dislocation }}+\varepsilon^{\text {diffusion }}
$$

The work of Shen on Haynes 282 relies on a hyperbolic sine function to mimic the shape of experimental creep curves and provides the portion of creep arising from the climb/glide of dislocations, $\varepsilon^{\text {dislocation }}$. However, this approach is not based in the physics of creep phenomena. Conversely, our model has developed the physics-based equivalent for $\varepsilon^{\text {dislocation }}$. Shen then adds additional creep strains due to diffusional processes that result in material damage which reduces the effective cross-sectional area carrying the applied load. The increased stress accelerates the creep rate, i.e., transition to tertiary creep.

$\dot{\varepsilon}^{\text {diffusion }}$ consists of four terms and each are dependent on the grain size:

$$
\begin{array}{lc}
\dot{\varepsilon}^{\text {boundary_diff }}=C\left(\frac{1}{d}\right)^{3} \sigma_{\text {Applied }}\left(1+\varepsilon^{\text {creep }}\right) & \text { eqn. } 1 \\
\dot{\varepsilon}^{\text {lattice_diff }}=D\left(\frac{1}{d}\right)^{2} \sigma_{\text {Applied }}\left(1+\varepsilon^{\text {creep }}\right) & \text { eqn. } 2 \\
\dot{\varepsilon}^{\text {cavity_bound_diff }}=\xi\left(\frac{l}{d}\right) \frac{\sigma_{\text {Applied }}}{\ln \left(1 / \bar{\omega}_{\text {boundary_diff }}\right)} & \text { eqn. } 3
\end{array}
$$




$$
\dot{\varepsilon}^{\text {cavity_surface_diff }}=\xi \alpha \frac{\sqrt{\bar{\omega}_{\text {surface_diff }}} \sigma_{\text {applied }}{ }^{2}}{\left(1-\bar{\omega}_{\text {surface_diff }}\right)^{3}}
$$

Where:

$$
\alpha=\frac{D_{S} \delta_{S}}{D_{b} \delta_{b}} \frac{1}{\sqrt{2}} \frac{l^{2}}{d \gamma}
$$

$D_{s} \delta_{s}, D_{b} \delta_{b}$ are the surface and grain boundary diffusion coefficients, respectively, $l$ is the distance between cavities, which we have found experimentally to be on the order of 5-10 $\mu \mathrm{m}$, Fig. 1, and, d, is the grain size.

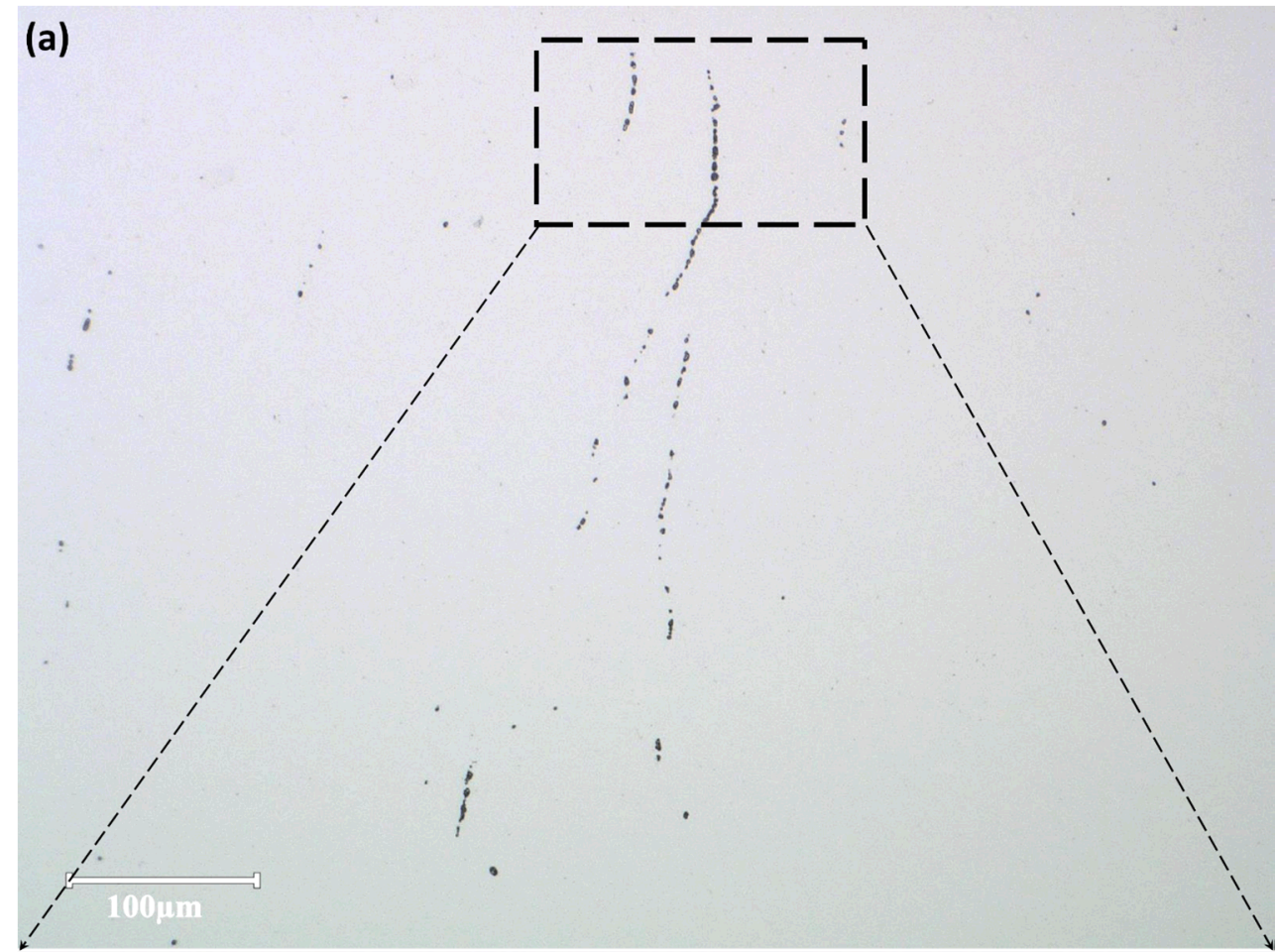

(b)

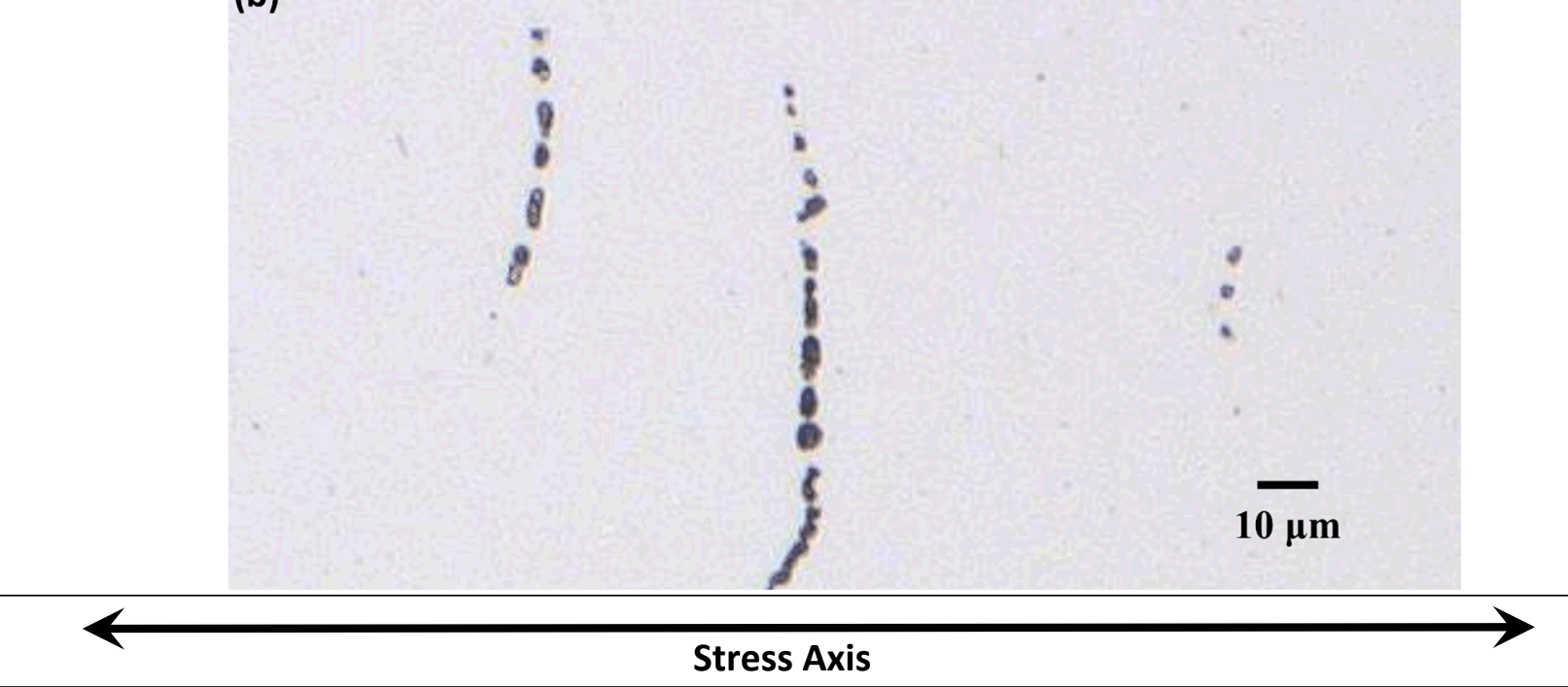

Figure 1. (a) Creep voids on grain boundaries in the weld of the gage section of a cross weld creep sample crept at $800^{\circ} \mathrm{C}$ and $240 \mathrm{MPa}$. (b) Enlarged view of the area outlined in (a). Void spacing is generally on the order of 5-10 $\mu \mathrm{m}$. 
It is evident that eqns. $3 \& 4$ are dependent on the reciprocal of the grain size to the first power while the grain size dependence in eqns. $1 \& 2$ enter in as the reciprocal grain size to the third and second power, respectively. Previous metallography of ruptured creep samples indicate that failure occurs in the weld metal in every case and, thus, creep damage must become localized in the weld metal. Creep damage localization will increase the effective stress in the weld and result in an increased creep rate in the weld metal as well as the total creep rate of the cross weld specimen. The grain size in the weld metal is quite large compared to the base metal. However, the grains of the weld are highly elongated with dimensions of $\sim 5000 \mu \mathrm{m}$ perpendicular to the stress axis and about $500 \mu \mathrm{m}$ in the direction parallel to the stress axis. This makes it somewhat difficult to define a "grain size" that is relevant to the equations above. However, since the applied stress is creating voids on grain boundaries exhibiting a grain boundary normal almost parallel to the applied stress (generally cavities are only observed on grain boundaries oriented approximately $\geq 45^{\circ}$ to the stress axis, Fig. 1), the grain dimensions in the direction parallel to the stress axis, $\sim 500 \mu \mathrm{m}$, would seem to be most relevant. Therefore, it can be assumed that Eqns. 3 and 4 will exert the biggest influence on creep behavior and it is expected that Eqns. 1 \& 2 can be neglected to a first approximation, although the magnitude of the coefficients in each equation need to be considered. Also, only Eqns. $3 \& 4$ contain the damage parameter, $\bar{\omega}$, and, thus, will become more influential as creep proceeds, providing the transition to tertiary creep:

$$
\bar{\omega}=1-A / A_{o} \quad \text { eqn. } 5
$$

where $A$ is the cross sectional area of the applied load.

According to Shen, the damage parameter is given by:

$$
\bar{\omega}=\bar{\omega}_{d i f f}+\bar{\omega}_{d i s l o} \quad \text { eqn. } 6
$$

The dislocation portion is considered to be a linear dependence on the creep strain attributable to dislocation motion [Shen, 2015]:

$$
\bar{\omega}_{\text {dislo }}=G \dot{\varepsilon}^{\text {dislo }} \quad \text { eqn. } 7
$$

where the dislocation strain rate is obtained from the model developed in this project. The diffusion component of eqn. 6 is given by:

$$
\bar{\omega}_{\text {diff }}=\bar{\omega}_{\text {boundary_diff }}+\bar{\omega}_{\text {surface_diff }} \quad \text { eqn. } 8
$$

And represents the damage by cavities that evolve by a combination of grain boundary and surface diffusion (along the cavity surface). (High grain boundary diffusion rates relative to surface diffusion rates tend to evolve lenticular cavities while high surface diffusion rates tend to keep the cavities spherical. Figure 1 tends to suggest that the latter condition prevails. Observations on other samples also indicate spherical voids on the grain boundaries of the welds.) These two mechanisms result in the following contributions to the evolution of the diffusion damage parameter as given by:

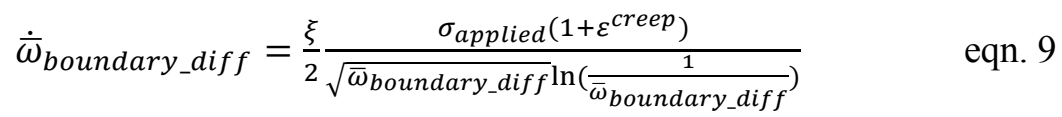

$$
\begin{aligned}
& \dot{\bar{\omega}}_{\text {surface_diff }}=\frac{\xi \alpha}{4} \frac{d}{\gamma} \frac{\sqrt{\bar{\omega}_{\text {surface_diff }}\left[\sigma_{\text {applied }}\left(1+\varepsilon^{\text {creep }}\right)\right]^{3}}}{\left(1-\bar{\omega}_{\text {boundary_diff }}\right)^{3}} \quad \text { eqn. } 10
\end{aligned}
$$

where $d$ is the grain size and $\gamma$ is the surface energy. 
As mentioned, the damage parameter has the effect of increasing the effective stress in the gage section:

$$
\sigma_{\text {eff }}=\frac{\sigma_{\text {applied }}}{(1-\bar{\omega})}\left(1+\varepsilon^{\text {creep }}\right)
$$

So now with Eqns. $3 \& 4,5,7,9,10$ and 11, the development of the damage parameter can be incorporated into the model as follows.

However, difficulties are encountered when incorporating Shen's scalar approach to the crystal plasticity model developed in this project. The applied stress in Shen work now becomes a tensor quantity in our model and its local value must be considered in the local creep behavior to obtain a realistic simulation of creep behavior. Therefore, an attempt will be made to extend the crystal plasticity model to include diffusion creep components based on the stress tensor. The advantages of inclusion into the current model is that complex stress states, e.g. a pressurized tube, can be accommodated and their effect on creep behavior studied and compared to uniaxial creep behavior.

Based in the discussion above, the evolution of $\mathrm{F}^{\mathrm{p}}$ can be represented as

$$
\begin{gathered}
\dot{F}^{p} F^{p-1}=\sum_{\alpha} \dot{\gamma}_{g l i d e}^{\alpha} S^{\alpha}+\sum_{\alpha} \dot{\gamma}_{\text {climb }}^{\alpha} N^{\alpha}+\dot{\varepsilon}^{\text {boundary }} \text { diff }+\dot{\varepsilon}^{\text {lattice }} \text { diff } \\
+\dot{\varepsilon}^{\text {cavity_bound_diff }}+\dot{\varepsilon}^{\text {cavity_surface_diff }}
\end{gathered}
$$

The last four terms are defined as

$$
\begin{array}{cc}
\dot{\varepsilon}^{\text {boundary } y_{\text {diff }}}=C\left(\frac{1}{d}\right)^{3} \frac{3}{2} \sigma^{\prime} & \text { eqn. } 13 \mathrm{a} \\
\dot{\varepsilon}^{\text {lattice_diff }}=D\left(\frac{1}{d}\right)^{2} \frac{3}{2} \sigma^{\prime} & \text { eqn. } 13 \mathrm{~b} \\
\dot{\varepsilon}^{\text {cavity_bound_diff }}=\xi\left(\frac{l}{d}\right) \frac{\frac{3}{2} \sigma_{\prime}}{\ln \left(1 / \bar{\omega}_{\text {boundary_diff })}\right.} & \text { eqn. } 13 \mathrm{c} \\
\dot{\varepsilon}^{\text {cavity_surface_diff }}=\xi \alpha \frac{\sqrt{\bar{\omega}_{\text {surface_diff }} \frac{3}{2} \sigma_{e} \sigma \prime}}{\left(1-\bar{\omega}_{\text {surface_diff }}\right)^{3}} & \text { eqn. } 13 \mathrm{~d}
\end{array}
$$

where $\sigma^{\prime}$ is the deviatoric stress and $\sigma_{e}=\left(\frac{3}{2} \sigma^{\prime}: \sigma^{\prime}\right)^{1 / 2}$ is the effective stress. Considering the damage parameter, the effective resolve shear stress is calculated as

$$
\tau_{e f f}^{\alpha}=\frac{\tau^{\alpha}}{1-\bar{\omega}}
$$

eqn. 14

and the evolution of $\bar{\omega}$ is given in Eqns. 6 to 10. Eqns. 12-14 will be the basis used to incorporate the damage arising from diffusional processes into the current model.

Data from all-weld-metal creep tests will be used to calibrate the model in areas containing weld metal. Additionally, a few creep tests on all-base-metal creep specimens are finishing up to provide calibration and verification data for the model in areas containing base metal. 
Completion of this task is targeted for $8 / 16 / 2019$

Reference:

C. Shen, "Modeling Long-term Creep Performance for Welded Nickel-base Superalloy Structures for Power Generation Systems", Topical Report: Constitutive Creep Model for Alloy 282, DOE/NETL Cooperative Agreement DE-FE0024027, 2015.

Milestone M, "Creep simulation of a welded joint in Alloy 740H"

This task will not start until after tertiary creep has been incorporated into the model and it has been fully calibrated with $500 \mathrm{hr}$, creep tests on cross weld creep specimens from $740 \mathrm{H}$ welds, using synthetic microstructures for cross welds in Alloy $740 \mathrm{H}$.

Completion of this task is now targeted for $8 / 30 / 2019$.

Milestone N, "Validation of creep simulation model via an Alloy $740 \mathrm{H}$ weld consisting of refined microstructure"

No progress on this task during the $3^{\text {rd }}$ quarter of FY19.

The completion date of this task is now targeted for 9/15/2019

ISSUES

\begin{tabular}{|l|l|}
\hline Report Prepared By & Date \\
\hline Thomas M. Lillo and Wen Jiang & $7 / 31 / 2019$ \\
\hline
\end{tabular}

